\title{
Interleukin-8 release from human neutrophils after phagocytosis of Listeria monocytogenes and Yersinia enterocolitica
}

\author{
R. ARNOLD and W. KÖNIG \\ Departments of Medical Microbiology and Immunology, AG Infektabwehr, Ruhr-Universität Bochum, \\ Universitätsstraße 150, 44780 Bochum, Germany
}

\begin{abstract}
The release of interleukin-8 (IL-8) from human neutrophils was investigated after their internalisation of the invasive bacteria Listeria monocytogenes and Yersinia enterocolitica. Three pairs of bacterial strains were used to study the influence of listeriolysin $O$, invasiveness and Yersinia virulence plasmid (pYV)-encoded proteins on neutrophil cytokine synthesis. The neutrophils secreted IL-8 into the culture supernate after exposure to all strains tested. With $L$. monocytogenes, the virulence factor listeriolysin $O$ had no effect on IL-8 secretion, whereas a non-invasive mutant induced greater IL-8 release than the corresponding invasive strain. With $Y$. enterocolitica, expression of virulence plasmid-encoded proteins appeared to be responsible for diminished IL-8 release. Northern blot analysis showed that the induced IL-8 release was always accompanied by an enhanced level of cytoplasmic IL-8 mRNA. Cytokine priming of neutrophils with granulocyte macrophage colony-stimulating growth factor (GM-CSF), unlike granulocyte colony-stimulating factor (G-CSF), led to further enhancement of IL8 secretion induced after internalisation of the bacteria. Again, the increased IL-8 release, from GM-CSF primed neutrophils, was accompanied by an increased level of cytoplasmic IL-8 mRNA. The results emphasise the role of IL-8 in neutrophil-mediated host defence mechanisms during the acute phase of $L$. monocytogenes and $Y$. enterocolitica infection.
\end{abstract}

\section{Introduction}

Neutrophils have been shown to play an important role during the early 'non-specific' phases of listeriosis and yersiniosis $[1,2]$. Yersinia enterocolitica, a gramnegative enteroinvasive bacterium, causes gastroenteritis [3, 4]. All pathogenic strains carry the $70-\mathrm{kb}$ Yersinia virulence plasmid (pYV) and express the adhesin YadA and a group of secreted proteins called Yersinia outer proteins (Yops) [5]. Recently, it was reported that YopH, a protein phosphotyrosine phosphatase, and YopE, which mediates distortion of actin microfilaments, are responsible for an inhibitory effect on phagocytosis $[6,7]$. The inhibitory effect on human neutrophils suggests that these professional phagocytes

Received 3 Dec. 1996; revised version accepted 7 May 1997.

Corresponding author: Professor W. König. Present address: Institute of Medical Microbiology, Otto-von-Guericke-University Magdeburg, Leipziger rue 44, D-39120 Magdeburg, Germany. play an important role during host defence against this invasive bacterium [8].

Listeria monocytogenes, a food-borne pathogen, is a gram-positive, facultatively intracellular bacterium [9]. By means of specific gene products for invasion (internalin, p60), pathogenic L. monocytogenes strains adhere to and penetrate the intestinal epithelium [10, 11]. Once liberated into the cytoplasm of the host target cell, after dissolution of the phagosome membrane by listeriolysin $\mathrm{O}$ [12], L. monocytogenes spreads from cell to cell [13]. Neutrophils appear to be part of the innate host defences during the onset of L. monocytogenes infection $[14,15]$. Mice depleted in vivo of neutrophils by use of antibody RB6-8C5 succumbed to sublethal doses of $L$. monocytogenes [1, 16], and granulocyte colony-stimulating factor (GCSF) had a beneficial effect on the course of infection in neutrophil-depleted mice $[17,18]$.

Numerous studies in mice have shown that cytokines are important for resistance to $L$. monocytogenes infection [19] and cytokine expression in the spleen 
correlated with an influx of neutrophils [20]. A growing body of evidence suggests that neutrophils are not only end-stage effector cells capable of phagocytosis and inflammatory mediator release [21], but that they have the potential to secrete multiple pro-inflammatory cytokines [22]. A previous study described the release of interleukin- $1 \beta$ (IL- $1 \beta$ ), IL-6 and tumour necrosis factor- $\alpha$ (TNF- $\alpha$ ) from human neutrophils after internalisation of $L$. monocytogenes and $Y$. enterocolitica strains [23]. After cell activation, neutrophils are also able to secrete the multifunctional cytokine IL-8 [24]. IL-8 is generally reported to be a pro-inflammatory cytokine because of its chemotactic and degranulating effects on neutrophils [25] and the central role of IL-8 in many inflammatory processes is well documented [26]. Thus, neutrophils, by secreting IL-8 after internalisation of $L$. monocytogenes and $Y$. enterocolitica, might contribute to host defence during the onset of infection. The effect of listeriolysin $O$, invasiveness and virulence plasmid (pYV)-encoded proteins on IL-8 release from neutrophils were analysed in this study with three bacterial strain pairs. Furthermore, priming studies were performed to determine the influence of the colony-stimulating factors G-CSF and granulocyte macrophage colonystimulating growth factor (GM-CSF) on IL-8 synthesis by neutrophils exposed to invasive bacteria.

\section{Materials and methods}

\section{Materials}

The following reagents were used: Ficoll 400 (Pharmacia, Uppsala, Sweden); macrodex (Schiwa, Glansdorf, Germany); metrizoate (Nycomed, Oslo, Norway); $[\alpha-$ ${ }^{32} \mathrm{P}$ ]-dCTP (specific activity: $111 \mathrm{TBq} / \mathrm{mmol}$ ) and ${ }^{3} \mathrm{H}-$ thymidine (specific activity: $3.18 \mathrm{TBq} / \mathrm{mmol}$ ) (NEN, Dreieich, Germany); nitrocellulose sheets (Schleicher and Schuell, Dassel, Germany); gentamicin and all fine chemicals (Sigma, Deisenhofen, Germany); cell culture media and supplements (Gibco, Europe Ltd, Karlsruhe, Germany). Recombinant human IL-8 (Calbiochem, Bad Soden, Germany) was used as control standard in the IL8 ELISA. Murine anti-human monoclonal IL-8 antibodies and goat-alkaline phosphatase-labelled antihuman IL-8 antibodies were a generous gift from Dr M. Ceska (Sandoz-Forschungsinstitut, Wien, Austria).
The IL-8 cDNA inserted into a bluescript vector (pBluescript II SK) was a generous gift from Dr D. P. Cerretti (Immunex, Seattle, Washington, USA) [27]. GM-CSF was supplied by Sandoz (Nürnberg, Germany). Listeriolysin O was purified to homogeneity by Prof. J. E. Alouf (Institut Pasteur, Paris, France).

The bacterial strains used and their characteristics are described in Table 1. The strain pair L. monocytogenes NCTC $7973\left(\mathrm{Hly}^{+}, \mathrm{Inv}^{+}\right)$and SLCC 5779 (rough variant: $\mathrm{Hly}^{+}, \mathrm{Inv}^{-}$) [11] and the isogenic strains L. monocytogenes Mackaness SLCC 5764 wild type (WT: $\mathrm{Hly}^{+}, \mathrm{Inv}^{+}$) and non-haemolytic Tn916 mutant (M3: $\mathrm{Hly}^{-}, \mathrm{Inv}^{+}$) [28] were kindly provided by Prof. Dr W. Goebel (Institute of Genetics and Microbiology, Würzburg, Germany). The strain pair $Y$. enterocolitica 108-C (serotype O3, virulence plasmid cured) and 108-P (serotype O3, virulence plasmid bearing) was a generous gift from Prof. Dr J. Heesemann (Institute of Medical Microbiology, Würzburg, Germany) [29].

\section{Bacterial growth}

L. monocytogenes strains were grown in brain heart infusion (BHI) broth overnight at $37^{\circ} \mathrm{C}$ with shaking $(150 \mathrm{rpm})$. This culture was used to inoculate $10 \mathrm{ml}$ of BHI medium and allowed to grow for a further $3.5 \mathrm{~h}$ at $37^{\circ} \mathrm{C}$. Y. enterocolitica strains were cultured overnight at $26^{\circ} \mathrm{C}$, then subcultured as above and grown for a further $4 \mathrm{~h}$ at $37^{\circ} \mathrm{C}$. The bacteria were centrifuged (4000 g, $20 \mathrm{~min}$ ), washed twice with PBS, and resuspended in RPMI-1640 medium to a concentration of $12.5 \times 10^{7}$ cells $/ 50 \mu 1$.

\section{Haemolysin assay}

Haemolytic activity of $L$. monocytogenes strains and of purified listeriolysin $\mathrm{O}$ was determined as follows. Bacteria $\left(2.5 \times 10^{8}\right.$ cells $\left./ 100 \mu 1\right)$, the culture supernate $(10-100 \mu \mathrm{l})$ or purified listeriolysin $\mathrm{O}$ were incubated for $30 \mathrm{~min}$ at $37^{\circ} \mathrm{C}$ with $900 \mu \mathrm{l}$ of a suspension containing sheep erythrocytes $2 \% \mathrm{v} / \mathrm{v}, 20 \mathrm{mM} \mathrm{CaCl}_{2}$, $10 \mathrm{mM}$ Tris and $160 \mathrm{mM} \mathrm{NaCl}$ adjusted to $\mathrm{pH} 5.5$ with $\mathrm{HCl}$. The mixture was kept for $20 \mathrm{~min}$ on ice and then centrifuged. The released haemoglobin in the supernate was determined photometrically at $530 \mathrm{~nm}$.

Table 1. Strains used in this study and their characteristics

\begin{tabular}{lccc}
\hline Strain & Serovar & $\begin{array}{c}\text { Listeriolysin } \\
\text { phenotype }\end{array}$ & $\begin{array}{c}\text { Invasion } \\
\text { phenotype }\end{array}$ \\
\hline L. monocytogenes & $1 / 2 \mathrm{a}$ & $\mathrm{Hly}^{+}$ & $\mathrm{Inv}^{+} \mathrm{p} 60^{+}$ \\
NCTC 7973 & $1 / 2 \mathrm{a}$ & $\mathrm{Hly}^{+}$ & $\mathrm{Inv}^{-} \mathrm{p}^{-}$ \\
SLCC 5779 & $1 / 2 \mathrm{a}$ & $\mathrm{Hly}^{+}$ & $\mathrm{Inv}^{+} \mathrm{p}^{+}$ \\
SLCC 5764 (Mackaness) WT & $1 / 2 \mathrm{a}$ & $\mathrm{Hly}^{-}$ & $\mathrm{Inv}^{+} \mathrm{p}^{+}$ \\
SLCC 5764 (Tn916 mutant) M3 & & & \\
Y. enterocolitica & $\mathrm{O} 3$ & & $\mathrm{Inv}^{+}$ \\
108-P (virulence plasmid-bearing) & $\mathrm{O}$ & & $\mathrm{Inv}^{+}$ \\
108-C (virulence plasmid-free) & & & \\
\hline
\end{tabular}




\section{Preparation of neutrophils}

Human neutrophils were prepared from heparinised venous blood of healthy donors on a Ficoll-metrizoate gradient followed by dextran sedimentation, as described previously [30]. The remaining erythrocytes were lysed by exposing the cells to hypotonic conditions. After preparation, neutrophils were washed twice with PBS (modified Dulbecco phosphate-buffered saline consisting of $137 \mathrm{mM} \mathrm{NaCl}, 8 \mathrm{mM} \mathrm{Na} 2 \mathrm{HPO}_{4}$, $2.7 \mathrm{mM} \mathrm{KH}_{2} \mathrm{PO}_{4}$, and $2.7 \mathrm{mM} \mathrm{KCl}, \mathrm{pH} 7.4$ ) and a third time with RPMI-1640 medium. This method gave a cell preparation containing $>97 \%$ pure neutrophils ( $1-2 \%$ eosinophils and $<2 \%$ mononuclear cells) as shown by morphological examination of Wright-stained smears and non-specific esterase staining.

\section{Phagocytosis of bacteria}

Bacteria were labelled by the addition of $\left[{ }^{3} \mathrm{H}\right]-$ thymidine $(55.5 \mathrm{kBq})$ to a $10-\mathrm{ml}$ volume of bacterial culture after incubation for $1 \mathrm{~h}$. The culture was incubated at $37^{\circ} \mathrm{C}$ for a further $2.5 \mathrm{~h}$, then the bacteria were washed twice in PBS and resuspended in RPMI1640 medium at $12.5 \times 10^{7}$ cells $/ 50 \mu \mathrm{l}$. The bacteria incorporated $40-60 \%$ of the added radioactivity [31]. For stimulation experiments, radioactively labelled neutrophils $\left(2 \times 10^{7} / \mathrm{ml}\right)$ in $500 \mu$ l of PBS were mixed with $50 \mu 1$ of the bacterial suspension in the absence of serum and incubated at $37^{\circ} \mathrm{C}$ for 5 or $30 \mathrm{~min}$. The neutrophils were then separated from the bacteria by centrifugation at $300 \mathrm{~g}$ for $15 \mathrm{~min}$. Adherent $Y$. enterocolitica were removed from the neutrophils by incubation for $30 \mathrm{~min}$ on ice with $500 \mu \mathrm{l}$ of PBS-EDTA (40 mM)-lysozyme $(100 \mu \mathrm{g} / \mathrm{ml})$; adherent $L$. monocytogenes were removed by treatment with PBS-EDTAlysozyme-lysostaphin $(1 \mu \mathrm{g} / \mathrm{ml})$. Neutrophils were lysed in distilled water to determine the percentage of ingested bacteria, determined by liquid scintillation counting (Rack beta 1209, LKB, Turku, Finland). The escape of listeriolysin O-producing L. monocytogenes strains into the cytoplasm of neutrophils was verified by microscopy.

\section{Stimulation experiments}

Neutrophil viability was determined by trypan blue exclusion and only cell preparations with a viability $>95 \%$ were used. Neutrophils $\left(5 \times 10^{6}\right)$ were exposed to $12.5 \times 10^{7}$ bacteria in a volume of $1 \mathrm{ml}$ (multiplicity of infection = 25:1). After culture for $1 \mathrm{~h}$ in RPMI1640 medium in a water-saturated atmosphere containing $\mathrm{CO}_{2} 5 \%$ at $37^{\circ} \mathrm{C}$, gentamicin $(50 \mu \mathrm{g} / \mathrm{ml})$ was added to prevent overgrowth of the neutrophils. For cytokine priming, GM-CSF $10 \mathrm{ng}$ or G-CSF $10 \mathrm{ng}$, diluted in RPMI-1640 medium, or the medium alone (as control), were added to neutrophils in a volume of $600 \mu$ l. After $15 \mathrm{~min}$, bacteria or medium were added. Unprimed neutrophils were incubated for $4 \mathrm{~h}$ to obtain maximal IL-8 release after exposure to $L$. monocyto- genes and $Y$. enterocolitica. With GM-CSF-priming, a culture time of $3 \mathrm{~h}$ was optimal. After incubation, cellconditioned media were harvested by centrifugation and stored at $-70^{\circ} \mathrm{C}$ until used for IL-8 determination.

\section{Cytokine immunoassay}

Interleukin- 8 was analysed by enzyme-linked immunosorbent assay (ELISA) as described previously [32]. This ELISA method detected IL-8 at concentrations $\geqslant 30 \mathrm{pg} / \mathrm{ml}$.

\section{RNA extraction and Northern blot analysis}

Total cellular RNA was extracted according to the protocol of Chomczynski and Sacci [33]. For Northern blot analysis, $20 \mu \mathrm{g}$ of total RNA were electrophoresed under denaturing conditions on an agarose $1.2 \% \mathrm{w} / \mathrm{v}-$ formaldehyde gel. The RNA was blotted on to GeneScreen Plus membranes (NEN, Dupont) by capillary transfer and hybridised under stringent conditions to a ${ }^{32} \mathrm{P}$-labelled nick-translated IL- 8 cDNA probe (a 300-bp KpnI/EcoRI cDNA fragment) [34]. Standardisation was performed with respect to the ethidium bromide-stained 28S and 18S rRNA of the blotted total RNA [27]. Equal RNA loading and transfer were checked by ultraviolet examination of the gels and blots. Blots were quantified by laser densitometry.

\section{Analysis of data}

All experiments were carried out at least three times. The data were calculated as mean and SEM. The significance was evaluated by the two-tailed Student's $t$ test for independent means; $p<0.05$ was considered significant.

\section{Results}

\section{Phagocytosis of bacteria}

The uptake of the three bacterial strain pairs by neutrophils after an incubation time of $30 \mathrm{~min}$ is depicted in Table 2. Similar phagocytosis data were obtained after an incubation time of $5 \mathrm{~min}$ (data not shown). The data are expressed as the percentage of

Table 2. Extent of bacterial phagocytosis by neutrophils

\begin{tabular}{lc}
\hline Strain & Mean percentage uptake (SEM) \\
\hline L. monocytogenes & \\
NCTC 7973 & $3.7(0.6)$ \\
SLCC 5779 & $17.3(2.1)$ \\
SLCC 5764 WT & $2.8(0.5)$ \\
SLCC 5764 M3 & $3.1(0.4)$ \\
Y. enterocolitica & \\
108-P & $20.3(3.5)$ \\
108-C & $28.4(2.9)$ \\
\hline
\end{tabular}


radioactively labelled bacteria taken up by the neutrophils. All the bacterial strains were phagocytosed. The uptake of the two invasive $Y$. enterocolitica strains $(>20 \%)$ differed significantly from that of the three invasive $L$. monocytogenes strains $(<5 \%)$. Only the non-invasive L. monocytogenes strain SLCC 5779, which forms long chains of cells, was phagocytosed extensively (17.3\%). The isogenic L. monocytogenes strain pair WT and M3 were internalised to the same degree, indicating that the virulence factor listeriolysin $\mathrm{O}$ did not influence the phagocytosis of $L$. monocytogenes by neutrophils. The virulence plasmid-cured $Y$. enterocolitica strain 108-C was readily phagocytosed (28.4\%), whereas uptake of virulence plasmid-bearing strain 108-P expression the Yops and YadA was only $20.3 \%$, verifying the anti-phagocytic activity of the pYV-encoded virulence factors.

\section{IL-8 release after internalisation of bacteria}

Human neutrophils were exposed to the bacterial strain pairs of L. monocytogenes and $Y$. enterocolitica for $4 \mathrm{~h}$. The amount of IL- 8 measured in the culture supernates was maximal after this incubation time and is shown in Fig. 1. As a positive control, the IL-8 release from neutrophils stimulated with Ca-ionophore A23187 is depicted. The isogenic L. monocytogenes strain pair WT and M3 induced similar IL-8 secretion from neutrophils (0.76 SEM 0.04 and 0.83 SEM $0.06 \mathrm{ng} / \mathrm{ml}$, respectively). Therefore, the virulence factor listeriolysin $\mathrm{O}$ did not appear to influence IL-8 release from human neutrophils. This result was verified by incubation of neutrophils with purified listeriolysin $\mathrm{O}$ $(0.1-10 \mathrm{U} / \mathrm{ml})$. No IL-8 synthesis was induced (data not shown). After incubation of neutrophils with the $L$. monocytogenes strain pair NCTC 7973 and SLCC

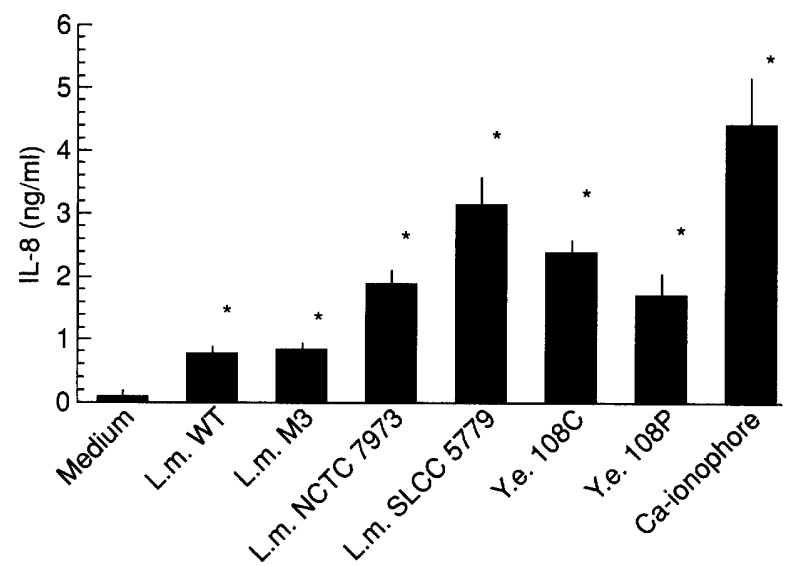

Fig. 1. IL-8 release from human neutrophils $\left(5 \times 10^{6}\right)$ cultured for $4 \mathrm{~h}$ in the presence of medium, $L$. monocytogenes WT, L. monocytogenes M3, L. monocytogenes NCTC 7973, L. monocytogenes SLCC 5779, Y. enterocolitica 108-C, Y. enterocolitica 108-P, and Caionophore A23187 $(6 \mu \mathrm{M})$, respectively; columns represent mean values $(\mathrm{ng} / \mathrm{ml})$ and vertical bars represent the $\mathrm{SEM} ; \mathrm{n}=4 ;{ }^{*} \mathrm{p}<0.05$ versus supernates from noninfected neutrophils (medium).
5779 , larger amounts of IL-8 were secreted into the culture supernate than with strain pair WT and M3. However, the invasive strain NCTC 7973 induced significantly lower amounts of IL-8 (1.88 SEM $0.22 \mathrm{ng} / \mathrm{ml}$ ) compared to the non-invasive L. monocytogenes strain SLCC 5779 (3.14 SEM $0.45 \mathrm{ng} / \mathrm{ml}$ ). Thus, the observed greater phagocytosis of the noninvasive strain correlated with an enhanced IL-8 secretion from neutrophils.

The internalisation of the two invasive $Y$. enterocolitica strains led to differences in IL-8 release from neutrophils. Both strains induced a significantly enhanced IL-8 synthesis compared to the constitutive IL-8 secretion of $98 \mathrm{pg} / \mathrm{ml}$ (Fig. 1, medium). This latter might be the result of an activation process due to the plastic surfaces of the incubation vials used. Strain 108-P induced a significantly lower IL-8 release than its isogenic, plasmid-free strain 108-C (1.70 SEM 0.14 versus $2.36 \mathrm{SEM} 0.31 \mathrm{ng} / \mathrm{ml}$ ). Thus, the lower phagocytosis of the plasmid-bearing strain 108-P, expressing the virulence factor YadA and the phagocytosis-inhibitory factors YopH and YopE, correlated with a diminished IL-8 release from neutrophils.

\section{IL-8 mRNA accumulation by neutrophils}

Northern blot analysis was performed to elucidate the molecular background of the observed IL-8 secretion pattern from human neutrophils after internalisation of the bacteria. Fig. 2 shows a representative IL-8 Northern blot from these experiments. At the bottom, the total RNA blotted on nitrocellulose and stained with ethidium bromide is presented, verifying that

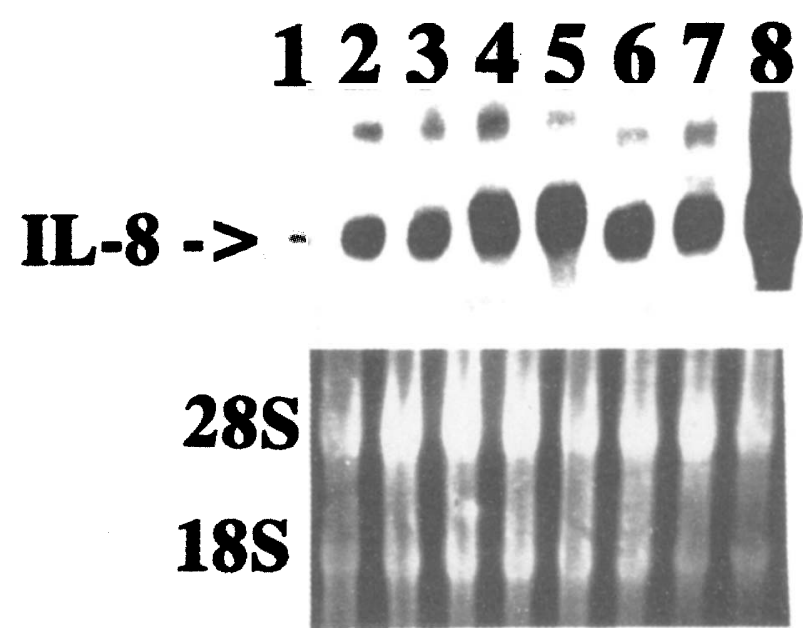

Fig. 2. Northern blots showing cytoplasmic IL-8 mRNA steady state levels in human neutrophils cultured for $2 \mathrm{~h}$. Neutrophils were incubated with (1) medium; (2) $L$. monocytogenes WT; (3) L. monocytogenes M3; (4) $L$. monocytogenes NCTC 7973; (5) L. monocytogenes SLCC 5779; (6) $Y$. enterocolitica 108-C; (7) $Y$. enterocolitica 108-P or (8) Ca-ionophore A23187 $(6 \mu \mathrm{M})$, respectively; bottom: ethidium bromide-stained total RNA after blotting on to the filter. 
equal amounts of RNA were analysed in each lane of the Northern blot shown. Compared to the medium control (lane 1) neutrophils accumulated IL-8 mRNA after incubation with each bacterial strain (lanes 2-7). As shown in lane 8, neutrophil stimulation with the Caionophore A23187 served as a positive control. The amounts of cytoplasmic IL-8 mRNA after phagocytosis of $Y$. enterocolitica 108-C and 108-P (lanes 6 and 7) were similar. Therefore, in comparison to strain 108-C the diminished IL-8 release observed after phagocytosis of strain 108-P was not due to a lower amount of IL-8 mRNA. In contrast, the isogenic L. monocytogenes strain pair WT and M3 (lanes 2 and 3) induced a lower cytoplasmic IL-8 mRNA level than the strain pair NCTC 7973 and SLCC 5779 (lanes 4 and 5). Therefore, the observed differences in the IL-8 secretion pattern induced by these $L$. monocytogenes strain pairs correlated with the amounts of IL- 8 mRNA in neutrophils measured after phagocytosis.

\section{$I L-8$ release from neutrophils after GM-CSF and G-CSF priming}

In the mouse model of $L$. monocytogenes infection, exogenously added colony-stimulating factor enhanced resistance of neutrophil-depleted mice as determined by increased survival and reduced bacterial growth. To examine the basis of this protective effect, IL-8 secretion by G-CSF- as well as by GM-CSF-primed neutrophils was determined. Fig. 3 shows the IL-8 release data from GM-CSF-primed neutrophils after incubation for $3 \mathrm{~h}$, the time of maximal IL- 8 release. It is evident that GM-CSF priming by itself induced an enhanced IL-8 release from neutrophils (0.13 SEM 0.1 versus $0.72 \mathrm{SEM} 0.2 \mathrm{ng} / \mathrm{ml}$ ). Furthermore, IL-8

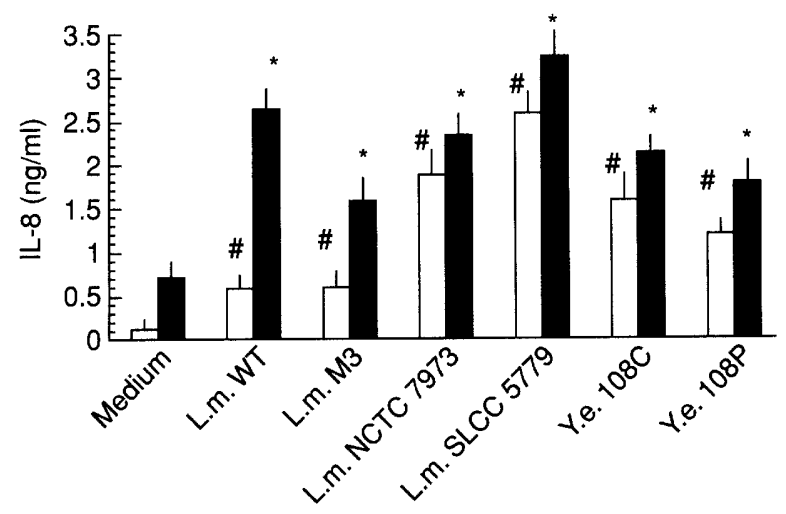

Fig. 3. IL-8 release from non-primed ( $\square$ ) and GM-CSFprimed $(10 \mathrm{ng} / \mathrm{ml})$ (品) human neutrophils $\left(5 \times 10^{6}\right)$ cultured for $3 \mathrm{~h}$. The cells were exposed to medium, $L$. monocytogenes WT, L. monocytogenes M3, L. monocytogenes NCTC 7973, L monocytogenes SLCC 5779, Y. enterocolitica $108-\mathrm{C}$ or $Y$. enterocolitica $108-\mathrm{P}$, respectively. Columns represent the mean values $(\mathrm{ng} / \mathrm{ml})$ and vertical bars represent the SEM of four experiments performed in triplicate; ${ }^{\#} \mathrm{p}<0.05$ versus supernates from non-primed, non-infected cells; ${ }^{*} \mathrm{p}<0.05$ versus supernatants from GM-CSF-primed, non-infected neutrophils. secretion due to internalisation of all bacterial strains under investigation was significantly enhanced by GMCSF priming. In contrast, G-CSF priming did not alter IL-8 release from neutrophils either exposed to $L$. monocytogenes and $Y$. enterocolitica strains or to medium alone (data not shown).

\section{IL-8 mRNA levels in GM-CSF- and G-CSF- primed neutrophils}

To determine whether the increased IL- 8 secretion of GM-CSF-primed neutrophils might be accompanied by an enhanced cytoplasmic IL- 8 mRNA level, Northern blot experiments were performed. Fig. 4 shows the amount of IL-8 mRNA after exposure of neutrophils to the pathogenic L. monocytogenes strain NCTC 7973. As can be seen, GM-CSF-primed neutrophils accumulated IL-8 mRNA (lane 2, 83\% of maximum) compared to the medium control (lane 1, 61\% of maximum). Neutrophils primed with G-CSF (lane 3, $58 \%$ of maximum) did not accumulate IL- 8 mRNA. The IL-8 accumulation induced after uptake of $L$. monocytogenes NCTC 7973 (lane 4, 85\% of maximum) was further enhanced in GM-CSF-primed neutrophils (lane $5,100 \%=$ maximum). In contrast, priming with

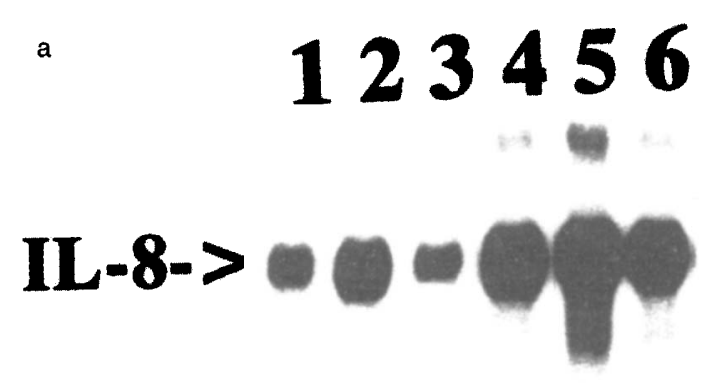

b

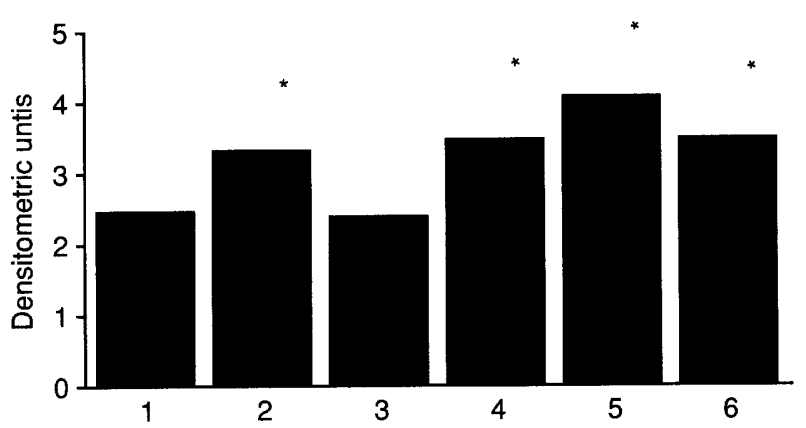

Fig. 4. (A) Expression of IL-8 mRNA in human neutrophils primed with GM-CSF or G-CSF and exposed to $L$. monocytogenes NCTC 7973. The cells were cultured for $2 \mathrm{~h}$ with (1) medium, (2) GM-CSF $(10 \mathrm{ng} / \mathrm{ml})$, (3) G-CSF (10 ng/ml), (4) L. monocytogenes NCTC 7973, (5) GM$\mathrm{CSF}+L$. monocytogenes NCTC 7973; (6) G-CSF $+L$. monocytogenes NCTC 7973; a representative Northern blot is presented. (B) Densitometry of the representative northern blot presented above; ${ }^{*} \mathrm{p}<0.05$ versus medium control $(\mathrm{n}=3)$. 
G-CSF was without any influence on the cytoplasmic IL-8 mRNA level induced by internalisation of $L$. monocytogenes NCTC 7973 (lane 6, 86\% of maximum).

\section{Discussion}

This study was performed to analyse the release of IL8 from human neutrophils after internalisation of the enteroinvasive bacteria $L$. monocytogenes and $Y$. enterocolitica. The data show that neutrophils secreted IL-8 after phagocytosis of both L. monocytogenes and $Y$. enterocolitica and there was a correlation between the amount of phagocytosed bacteria and IL-8 secretion. The non-invasive $L$. monocytogenes strain SLCC 5779, growing in long cell filaments [11], was phagocytosed most readily and induced the highest IL-8 release. Therefore, the property of invasiveness for epithelial cells plays no role with regard to phagocytosis and IL-8 induction by neutrophils. In contrast, epithelial cells secreted IL- 8 only after their infection by invasive bacteria [35]. Although the phagocytic process is finished as early as $5 \mathrm{~min}$ after exposure to the bacteria, it seems to be the stimulus for enhanced IL- 8 gene expression up to $4 \mathrm{~h}$ afterwards [36]. On further incubation, decreased cell viability and perhaps IL-8 degradative processes due to aminopeptidase $\mathrm{N}$ might be responsible for the reduced IL-8 levels found in the culture supernates (data not shown) [37].

IL- 8 release and IL- 8 mRNA levels after uptake of the isogenic L. monocytogenes strain pair WT and M3 were similar. These data suggest that one of the most important virulence factors of $L$. monocytogenes, listeriolysin $\mathrm{O}$, does not excite neutrophils for enhanced IL-8 synthesis. This result was further substantiated by experiments with purified listeriolysin $O$. In contrast, the positive effect of listeriolysin $\mathrm{O}$ on IL-1 and TNF- $\alpha$ synthesis by murine macrophages has been reported $[38,39]$. We have also observed an increased IL-8 release from human peripheral blood mononuclear cells (c. 20\% monocytes, $80 \%$ lymphocytes) incubated with purified listeriolysin $O$ (unpublished observations). Therefore, it seems that the virulence factor listeriolysin $\mathrm{O}$ induces IL-8 gene expression in a cell type specific manner. It remains to be determined whether murine granulocytes are able to express IL-8 after exposure to listeriolysin O.

L. monocytogenes strains WT and NCTC 7973 were similarly phagocytosed by neutrophils, but the strain NCTC 7973 induced the release of twice as much IL8 compared to strain WT. Recently, Vasquez and coworkers reported that listeriolysin $\mathrm{O}$ by itself was not primarily responsible for TNF- $\alpha$ release from murine macrophages [38]. They suggested that listeriolysin O, by disruption of the phagolysosome, allows other bacterial molecules liberated into the cytoplasm to induce TNF- $\alpha$ release. It may be that strains WT and
NCTC 7973 differ in the production of other molecules which are responsible for the observed differences in IL-8 release from neutrophils.

The amount of IL-8 released upon phagocytosis of $Y$. enterocolitica strain 108-P was reduced in comparison with that released upon uptake of strain 108-C. Yersinia outer proteins (Yops) and YadA encoded by the virulence plasmid play an important role in inhibiting the ingestion of $Y$. enterocolitica by neutrophils $[7,8]$. Therefore, one reason for the diminished IL-8 release by neutrophils after uptake of strain 108$\mathrm{P}$ might be the reduced phagocytosis of this virulence plasmid carrying strain. Recently, Schulte and coworkers [40] reported that epithelial cells infected with a virulence plasmid-bearing $\left(\mathrm{pYV}^{+}\right) Y$. enterocolitica strain released lower amounts of IL-8 than epithelial cells infected with an isogenic non-virulent, plasmid-cured $\left(\mathrm{pYV}^{-}\right)$strain. Neither the lower infection rate of the virulent $\mathrm{pYV}^{+}$strain nor the cytotoxic potential of YopE and YopH - known to inhibit phagocytosis by neutrophils - was responsible for the reduced IL-8 secretion pattern. However, YopB and YopD were involved in the suppression of IL-8 release from epithelial cells as well as in the TNF- $\alpha$ release from murine macrophages $[40,41]$, but the mechanism of this inhibitory effect is unknown.

IL-8 secretion by the neutrophils correlated with enhanced cytoplasmic IL-8 mRNA levels, suggesting an increased rate of IL-8 gene transcription or an altered IL-8 mRNA stability. No differences were observed in the amount of IL-8 mRNA induced by $L$. monocytogenes NCTC 7973 and SLCC 5779 or by $Y$. enterocolitica 108-C and 108-P, respectively (Fig. 2). It is possible that the observed differences in IL-8 release might have been due to enhanced secretion of the cytoplasmic IL-8 pool. A recent study has shown that the phagocytosis of $L$. monocytogenes and $Y$. enterocolitica diminished the respiratory burst activity and altered the leukotriene metabolism of human neutrophils [31]. In contrast, the release of the proinflammatory cytokines TNF- $\alpha$, IL- $1 \beta$ and IL- 6 from human neutrophils was induced after exposure to these invasive bacteria [23]. Also, murine macrophages exposed to L. monocytogenes showed a suppressed respiratory burst but an increased IL-1 synthesis [39]. The protective role of IL-1, IL- 6 and TNF- $\alpha$ against a $L$. monocytogenes infection of mice was described recently [38, 42, 43]. As IL-8 activates neutrophils for chemotaxis, exocytosis, receptor expression and respiratory burst [25], the data from the present study suggest that neutrophils, by secreting the pre-inflammatory cytokines IL- $1 \beta$, IL-6, TNF- $\alpha$ and IL-8, might overcome the dysfunctions in mediator release and phagocytic activity induced by these bacteria [23, 31].

The observed IL-8 release from epithelial cells subsequent to infection with either $L$. monocytogenes or $Y$. enterocolitica [35], emphasises the role of this 
cytokine during the early phase of infection by these bacteria. Therefore, neutrophils chemotactically recruited and activated by IL- 8 in a paracrine or autocrine manner, or both, should be well armed for phagocytosis of $Y$. enterocolitica $[7,8]$ and of cytolysis of $L$. monocytogenes-infected cells $[14,15$, 44].

Epithelial cells are also able to synthesise GM-CSF [45]. The present study clearly revealed that human neutrophils primed with GM-CSF accumulated more IL- 8 mRNA and secreted more IL- 8 into the culture supernate than unprimed cells. In contrast, G-CSF priming showed no influence on either IL-8 protein or IL-8 mRNA levels. The data suggest that epithelial cells of mucosal surfaces might prime recruited neutrophils for an enhanced IL-8 release and effector cell functions in $L$. monocytogenes and $Y$. enterocolitica infections [46].

An essential contribution of neutrophils in the course of cell-mediated immunity during primary and secondary infections was recently observed [47, 48]. There is some evidence that IL-8 is also chemotactic for T-lymphocytes and suppresses IL-4 production by $\mathrm{CD}^{+} \mathrm{T}$ cells [49]. One may speculate that neutrophils, by secreting IL-8, are involved in the generation of protective Th1-mediated cellular immune responses.

In agreement with our previous study on cytokine release from human neutrophils exposed to $L$. monocytogenes and $Y$. enterocolitica [23], the present data on IL-8 suggest that neutrophils modulate the cytokine network in infected tissue. During the course of $L$. monocytogenes or $Y$. enterocolitica infection, the neutrophil might be involved in protective inflammatory as well as immune responses.

\section{References}

1. Rogers HW, Unanue ER. Neutrophils are involved in acute, nonspecific resistance to Listeria monocytogenes in mice. Infect Immun 1993; 61: 5090-5096.

2. Autenrieth IB, Firsching R. Penetration of $M$ cells and destruction of Peyer's patches by Yersinia enterocolitica: an ultrastructural and histological study. J Med Microbiol 1996; 44: $285-294$.

3. Cover TL, Aber RC. Yersinia enterocolitica. $N$ Engl $J$ Med 1989; 321: 16-24.

4. Miller VL. Yersinia invasion genes and their products. ASM News 1992; 58: 26-33.

5. Straley SC, Skrzypek E, Plano GV, Bliska JB. Yops of Yersinia spp. pathogenic for humans. Infect Immun 1993; 61: 31053110 .

6. Green SP, Hartland EL, Robins-Browne RM, Phillips WA. Role of YopH in the suppression of tyrosine phosphorylation and respiratory burst activity in murine macrophages infected with Yersinia enterocolitica. J Leukoc Biol 1995; 57: 972-977.

7. Ruckdeschel K, Roggenkamp A, Schubert S, Heesemann J. Differential contribution of Yersinia enterocolitica virulence factors to evasion of microbicidal action of neutrophils. Infect Immun 1996; 64: 724-733.

8. Visser LG, Annema A, van Furth R. Role of Yops in inhibition of phagocytosis and killing of opsonized Yersinia enterocolitica by human granulocytes. Infect Immun 1995; 63: 2570-2575.
9. Farber JM, Peterkin PI. Listeria monocytogenes, a food-borne pathogen. Microbiol Rev 1991; 55: 476-511.

10. Gaillard J-L, Berche P, Frehel C, Gouin E, Cossart P. Entry of L. monocytogenes into cells is mediated by internalin, a repeat protein reminiscent of surface antigens from gram-positive cocci. Cell 1991; 65: 1127-1141.

11. Kuhn M, Goebel W. Identification of an extracellular protein of Listeria monocytogenes possibly involved in intracellular uptake by mammalian cells. Infect Immun 1989; 57: 55-61.

12. Kuhn M, Kathariou S, Goebel W. Hemolysin supports survival but not entry of the intracellular bacterium Listeria monocytogenes. Infect Immun 1988; 56: 79-82.

13. Tilney LG, Tilney MS. The wiley ways of a parasite: induction of actin assembly by Listeria. Trends Microbiol 1993; 1: $25-$ 31 .

14. Conlan JW, North RJ. Neutrophil-mediated dissolution of infected host cells as a defense strategy against a facultative intracellular bacterium. $J$ Exp Med 1991; 174: 741-744.

15. Conlan JW, North RJ. Neutrophil-mediated lysis of infected hepatocytes. ASM News 1993; 59: 563-567.

16. Czuprynski CJ, Brown JF, Maroushek N, Wagner RD, Steinberg H. Administration of anti-granulocyte mAb RB6$8 \mathrm{C} 5$ impairs the resistance of mice to Listeria monocytogenes infection. J Immunol 1994; 152: 1836-1846.

17. Serushago BA, Yoshikai Y, Handa T, Mitsuyama M, Muramori K, Nomoto K. Effect of recombinant human granulocyte colony-stimulating factor (rh-CSF) on murine resistance against Listeria monocytogenes. Immunology 1992; 75: 475-480.

18. Kayashima S, Tsuru S, Hata N, Rokutanda M. Therapeutic effect of granulocyte colony-stimulating factor (G-CSF) on the protection against Listeria infection in SCID mice. Immunology 1993; 80: 471-476.

19. Mielke MEA, Ehlers S, Hahn H. The role of cytokines in experimental listeriosis. Immunobiology 1993; 189: 285-315.

20. Kratz SS, Kurlander RJ. Characterization of the pattern of inflammatory cell influx and cytokine production during the murine host response to Listeria monocytogenes. J Immunol 1988; 141: 598-606.

21. König W, Schönfeld W, Raulf $\mathrm{M}$ et al. The neutrophil and leukotrienes - role in health and disease. Eicosanoids 1990; 3: $1-22$.

22. Cassatella MA. The production of cytokines by polymorphonuclear neutrophils. Immunol Today 1995; 16: 21-26.

23. Arnold R, Scheffer J, König B, König W. Effects of Listeria monocytogenes and Yersinia enterocolitica on cytokine gene expression and release from human polymorphonuclear granulocytes and epithelial (HEp-2) cells. Infect Immun 1993; 61: 2545-2552.

24. Strieter RM, Kasahara K, Allen RM et al. Cytokine-induced neutrophil-derived interleukin-8. Am J Pathol 1992; 141: $397-$ 407.

25. Baggiolini M, Walz A, Kunkel SL. Neutrophil-activating peptide-1/interleukin 8 , a novel cytokine that activates neutrophils. J Clin Invest 1989; 84: 1045-1049.

26. Harada A, Sekido N, Akahoshi T, Wada T, Mukaida N, Matsushima K. Essential involvement of interleukin-8 (IL-8) in acute inflammation. J Leukoc Biol 1994; 56: 559-564.

27. Matsushima K, Morishita K, Yoshimura $\mathrm{T}$ et al. Molecular cloning of a human monocyte-derived neutrophil chemotactic factor (MDNCF) and the induction of MDNCF mRNA by interleukin 1 and tumor necrosis factor. $J \operatorname{Exp} \operatorname{Med} 1988$; 167: $1883-1893$

28. Kathariou S, Metz P, Hof $H$, Goebel W. Tn916-induced mutations in the hemolysin determinant affecting virulence of Listeria monocytogenes. J Bacteriol 1987; 169: 1291-1297.

29. Heesemann J, Algermissen B, Laufs R. Genetically manipulated virulence of Yersinia enterocolitica. Infect Immun 1984; 46: $105-110$.

30. Böyum A. A one stage procedure for isolation of granulocytes and lymphocytes from human blood. General sedimentation properties of white blood cells in $1 \mathrm{~g}$ gravity field. Scand $J$ Clin Lab Invest 1968; Suppl 97: 51-76.

31. Gröne M, Scheffer J, König W. Modulation of leukotriene generation by invasive bacteria. Immunology 1992; 77: 400-407.

32. Arnold R, Humbert B, Werchau H, Gallati H, König W. Interleukin-8, interleukin-6, and soluble tumor necrosis factor receptor type I release from a human pulmonary epithelial cell line (A549) exposed to respiratory syncytial virus. Immunology 1994; 82: 126-133. 
33. Chomczynski P, Sacchi N. Single-step method for RNA isolation by acid guanidinium thiocyanate-phenol-chloroform extraction. Anal Biochem 1987; 162: 156-159.

34. Feinberg AP, Vogelstein B. A technique for radiolabeling DNA restriction endonuclease fragments to high specific activity. Anal Biochem 1983; 132: 6-13.

35. Eckmann L, Kagnoff MF, Fierer J. Epithelial cells secrete the chemokine interleukin- 8 in response to bacterial entry. Infect Immun 1993; 61: 4569-4574.

36. Bazzoni F, Cassatella MA, Rossi F, Ceska M, Dewald B, Baggiolini M. Phagocytosing neutrophils produce and release high amounts of the neutrophil-activating peptid 1/interleukin8. J Exp Med 1991; 173: 771-774.

37. Kanayama N, Kajiwara $\mathrm{Y}$, Goto $\mathrm{J}$ et al. Inactivation of interleukin- 8 by aminopeptidase $\mathrm{N}$ (CD13). J Leukoc Biol 1995; 57: 129-134.

38. Vasquez MA, Sicher SC, Wright WJ et al. Differential regulation of TNF- $\alpha$ production by listeriolysin-producing versus non-producing strains of Listeria monocytogenes. $J$ Leukoc Biol 1995; 58: 556-562.

39. Yoshikawa H, Kawamura I, Fujita M, Tsukada H, Arakawa M, Mitsuyama M. Membrane damage and interleukin-1 production in murine macrophages exposed to listeriolysin $\mathrm{O}$. Infect Immun 1993; 61: 1334-1339.

40. Schulte R, Wattiau P, Hartland EL, Robins-Browne RM, Cornelis GR. Differential secretion of interleukin-8 by human epithelial cell lines upon entry of virulent or nonvirulent Yersinia enterocolitica. Infect Immun 1996; 64: 2106-2113.

41. Beuscher HU, Rödel F, Forsberg Å, Röllinghoff M. Bacteria evasion of host immune defense: Yersinia enterocolitica encodes a suppressor for tumor necrosis factor alpha expression. Infect Immun 1995; 63: 1270-1277.

42. Rogers HW, Tripp CS, Schreiber RD, Unanue ER. Endogenous IL-1 is required for neutrophil recruitment and macrophage activation during murine listeriosis. J Immunol 1994; 153: 2093-2101.

43. Dalrymple SA, Lucian LA, Slattery $\mathrm{R}$ et al. Interleukin-6 deficient mice are highly susceptible to Listeria monocytogenes infection: correlation with inefficient neutrophilia. Infect Immun 1995; 63: 2262-2268.

44. Conlan JW. Early pathogenesis of Listeria monocytogenes infection in the mouse spleen. $J$ Med Microbiol 1996; 44: $295-302$.

45. Jung HC, Eckmann L, Yang S-K et al. A distinct array of proinflammatory cytokines is expressed in human colon epithelial cells in response to bacterial invasion. $J$ Clin Invest 1995; 95: 55-65.

46. Khwaja A, Carver JE, Lynch DC. Interactions of granulocytemacrophage colony-stimulating factor (CSF), granulocyte CSF, and tumor necrosis factor $\alpha$ in the priming of the neutrophil respiratory burst. Blood 1992; 79: 745-753.

47. Appelberg R, Castro AG, Silva MT. Neutrophils as effector cells to T-cell-mediated, acquired immunity in murine listeriosis. Immunology 1994; 83: 302-307.

48. Rakhmilevich AL. Neutrophils are essential for resolution of primary and secondary infection with Listeria monocytogenes. $J$ Leukoc Biol 1995; 57: 827-831.

49. Gesser $\mathrm{B}$, Lund $\mathrm{M}$, Lohse $\mathrm{N}$ et al. IL-8 induces $\mathrm{T}$ cell chemotaxis, suppresses IL-4, and upregulates IL-8 production by $\mathrm{CD}^{+}$T cells. J Leukoc Biol 1996; 59: 407-411. 